\title{
Role of the Immunohistochemical Marker (Ki67) in Diagnosis and Classification of Hydatidiform Mole
}

Hasan Abu Deka FFa , Abd Ali Al Saeng ZH $\mathrm{H}^{b}$, Khalid Almukhtar Z ${ }^{c}$

${ }^{a}$ Department of pathology, Collage of Medicine, Kerbela University,Iraq

bepartment of Pathology, Medical city, Iraq

'Department of Pathology, Collage of Medicine, Baghdad University, Iraq

ABSTRACT

Introduction: Since the hallmark of gestational trophoblastic disease is trophoblastic proliferation, Ki67 is regarded as the best marker in studying hydatidiform mole. This study was conducted to evaluate the role of this proliferative marker in distinguishing among hydropic abortion, partial and complete hydatidiform mole. Materials and methods: This is a cross sectional study involving the application of Ki67 on a total of 90 histological samples of curetting materials from molar (partial and complete mole) and non molar hydropic abortion belong to Iraqi females, so three study groups were created. Immunohistochemical expression in villous cytotrophoblasts, syncytiotrophoblasts and stromal cells were recorded separately by three independent observers and the results were correlated statically. Results: The mean number of stained nuclei of villous cytotrophoblasts and stromal cells was the highest in complete mole and the lowest in non molar hydropic abortion. There is a significant statistical relationship regarding Ki67 labeling index in villous cytotrophoblasts between partial moles and hydropic abortion, complete mole and partial moles, hydropic abortion and complete mole. Regarding Ki67 labelling index in villous stromal cells, a significant statistical relationship achieved when the correlation done between partial mole and hydropic abortions, hydropic abortion and complete mole, while a non significant statistical relationship was achieved if the correlation done between partial and complete mole. All villous syncytiotrophoblasts showed negative results. Conclusion: Ki-67 labeling index in villous cytotrophblastic cells are useful in separating between partial moles and hydropic abortion, partial mole and complete mole, hydropic abortion and complete mole. While Ki-67 labeling index in villous stromal cells is only useful in separating between partial moles and hydropic abortion, hydropic abortion and complete mole.

KEYWORDS: Gestational trophoblastic disease, partial mole, complete mole, hydropic abortion

\section{INTRODUCTION}

Gestational trophoblastic diseases (GTD) are groups of disorders of fertilization that include complete and partial molar pregnancies, invasive mole, choriocarcinoma and the very rare placental site trophoblastic tumor (PSTT). ${ }^{24}$ Hydatidiform mole is regarded as the most common type of GTD. ${ }^{1}$ There are two subtypes of hydatidiform mole, partial and complete mole, the distinction between them relies mainly on both genetic and histological criteria. 9,22 At gynecological department trophoblastic diseases

Corresponding author:

Dr. Farah Falah Hassan Abu Deka

Department of Pathology,

College of Medicine, Kerbela University,

Al Sarafia Street, Bagdad Iraq.

Tel No: +07706084653

Email: dr.farah.histopathology@gmail.com often diagnosed when the serum human chorionic gonadotrophin levels plateau or rise in patients being observed after the an initial suspicion of hydatidiform mole. ${ }^{16}$ Most hydatidiform mole are sporadic however a familial syndrome of recurrent hydatidiform mole has been recorded. ${ }^{10}$ Genetically a complete mole is diploid without maternal contribution, whereas a partial mole is triploid with a maternal chromosome complement. ${ }^{15}$ It is very important to distinguish complete hydatidiform mole from partial hydatidiform moles, and non-molar hydropic abortion, because the risk of persistent trophoblastic disease is very high in complete one. ${ }^{4,14}$ The histomorphologic separation between hydropic abortion, partial and complete mole sometime very difficult ${ }^{12}$ and the fact that abortion due to chromosomal abnormalities 
sometimes produce a histological feature indistinguishable from partial mole made the bmatter worse. ${ }^{7,18}$ Partial mole is differentiated histologically from complete mole by the presence of two types of chorionic villi (enlarged, hydropic, and normal sized villi with sclerotic stroma); mild focal trophoblastic hyperplasia; villus scalloping often containing trophoblastic inclusions; and presence of fetal red blood cells in the stromal villous vasculature. ${ }^{7}$ On the other hand complete mole characterize by diffuse villous enlargement with marked hydropic changes, cistern formation and marked trophoblastic hyperplasia usually in a circumferential pattern with a remarkable cytological atypia. ${ }^{22}$ Hydropic abortion is regarded as a benign degenerative changes characterized by swelling of villi associated with minimal to absent cistern formation, neither abnormal trophoblastic proliferation nor atypia is present. ${ }^{24}$

DNA polymorphisms and polymerase chain reaction are probably the best accepted method of genetic analysis of gestational trophoblastic diseases, but it is time-consuming, expensive, requires skilled personnel and special facilities, it required both maternal and paternal blood samples in addition to molar tissue. ${ }^{14}$ One of the advantages immunohistochemistry is the ability to apply them retrospectively to sections of routinely formalinfixed and paraffin-embedded tissue that preclude the need for expensive or sophisticated equipments. $^{18}$ Recent studies revealed that expression of the paternally imprinted gene ( $p 57)$ is of particular help in differentiation between partial and complete mole, however it doesn't differentiate between partial mole and hydropic abortion and the positively stained villous intermediate trophoblasts sometimes account for false interpretation. ${ }^{11}$ Histologically confirmed cases ofhydatidiform mole should be included in the formal serum human chorionic gonadotropin follow-up and management of GTD should be established. ${ }^{19,21} \mathrm{Ki}-67$ gene encodes a nuclear protein having 2 isoforms, Ki-67 immunoreactivity presents in all cell cycle phases except in the quiescent G0 phase thus it reflects cellular proliferation, ${ }^{8}$ Over expression is frequently seen in various malignancy and associated with worse overall survival in bladder, brain, breast, kidney, lung, ovary, prostate, and thyroid cancer ${ }^{21}$, Furthermore Ki-67 reactivity is established in addition to other parameters in the World Health Organization's recommended grading system for neuroendocrine tumors. ${ }^{13}$ Because $\mathrm{Ki}-67$ has been established as a valuable reflection of the tissue proliferative compartment and thus could be of value in studying the biologic behavior of the gestational trophoblastic disease. ${ }^{17}$ Its expression in gestational trophoblastic diseases became an interested topic for many gynecological and pathological researchers worldwide with a variable recorded results. This study was conducted to evaluate the role of this proliferative marker in distinguishing among Iraqi females with hydropic abortion, partial and complete mole and to compare with the results of previous similar worldwide studies.

\section{MATERIALS AND METHODS}

\section{Materials selection}

In this cross sectional study, a total of 90 blocks of formalin-fixed, paraffin-embedded tissue for cases diagnosed as molar pregnancy and hydropic abortion were retrieved from the patient archive in the histopathology department of teaching laboratories in the medical city complex at Bagdad (in the period from January 2016 to February 2017). The only clinical information available for each case was a female's age. From each block two histological sections were made, one stained with routine hematoxyline and eosine for morphological evaluation and the other for immunohistochemical staining with Ki67 antibody using slandered immunohistochemical protocols. After morphological reevaluation (thorough searching at different magnifications) by three pathologists who had no idea about the previous diagnosis using the published criteria for diagnosis and classifications of hydatidiform mole, 30 cases were agreed to be partial mole and 30 complete mole and 30 hydropic abortion, so three study groups were made.

\section{Immunohistochemistry staining}

Immunohistochemical staining was performed by the application of a commercially available Ki67 immunohistochemical kit (Clone MIB-1, mouse monoclonal antibody, dilution 1:75-1:50, Dako) with envision detection system. A section from tonsil regarded as a positive control, negative control slides were prepared by omitting the primary antibody. In order to perform immunohistochemical 
staining on each block, 5 micrometer sections were made and applied the section on a positive charge dewaxing paraffin-embedded sections, after antigen retrieval was performed the tissue section was covered with peroxide blocking solution for 5 minutes followed by incubation of Primary antibody for 30 minutes, then the tissue section was covered with PolyExcel poly HRP and incubate for 30 minutes at room temperature, working solution and incubate for 5 minutes at room temperature, and lastly Hematoxyline stain was applied.

\section{Histopathological observation}

All immunohistochemically stained sections were evaluated independently by the same three pathologists under a light microscope using a microscope (Leica DM500), only sections that contain more than ten chorionic villi were evaluated. Immunohistochemical expression analyses for villous cytotrophoblasts, syncytiotrophoblasts and stromal cells were made separately in the most representative area for $\mathrm{Ki}-67$ (the area with the most concentrated immunohistochemically labeled nuclei of trophoblastic cells in medium sized villi), and the results described as (number of positive nuclei per total number of nuclei counting 100 cells of each population). ${ }^{8}$ Only nuclear staining plus mitotic figures should be included in the Ki67 scoring, the median time required for nuclei counting was 4 minutes.

\section{STATISTICAL ANALYSIS}

One way ANOVA with post hoc Tukey's test used to compare mean values of nuclei stained with Ki67 of different study groups. Results were expressed as mean \pm standard deviation. The differences were considered statistically significant when $\mathrm{p}$ value $<0.05$. All statistical tests were done by using IBM SPSS v. 24 software.

Photographs taken in this study by the camera (Leica Icc 50E).

This study was approved by the ethical committee of the national center for educational laboratories and done in accordance with it is institutional policy in which patient consent was taken at the beginning of consultation to teaching laboratories for any future retrospective studies.

\section{RESULTS}

The study enrolled 90 cases of hydatidiform moles, 30 were the partial mole and 30 were the complete mole and 30 were hydropic abortion (figure 1, 2 and 3 ), so three study groups were created, age range of cases diagnosed as hydatidiform mole was from 15 years to 48 years with a mean age $27.13 \pm 1.28$ years.

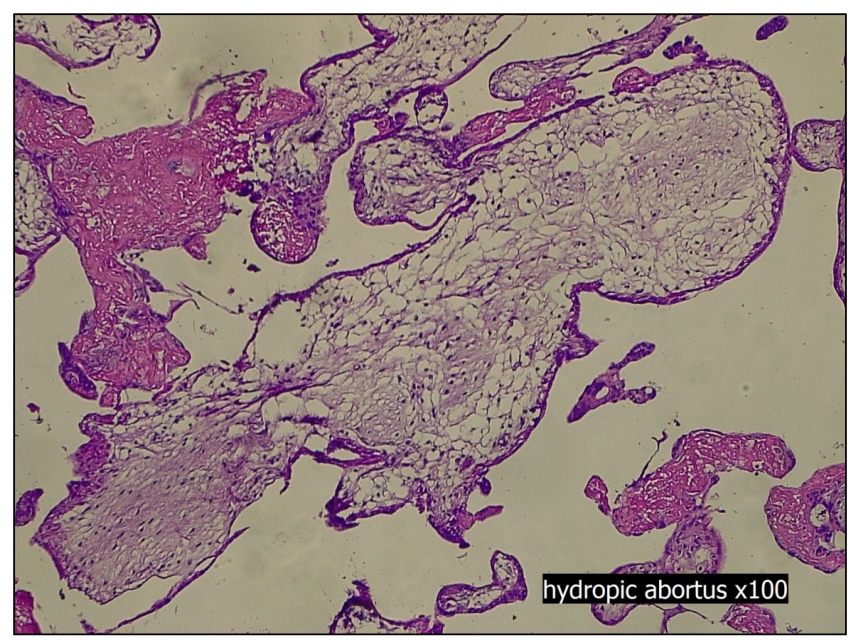

Figure 1: Hematoxyline and Eosin stained tissue section showing the histological features of hydropic abortion (100x)

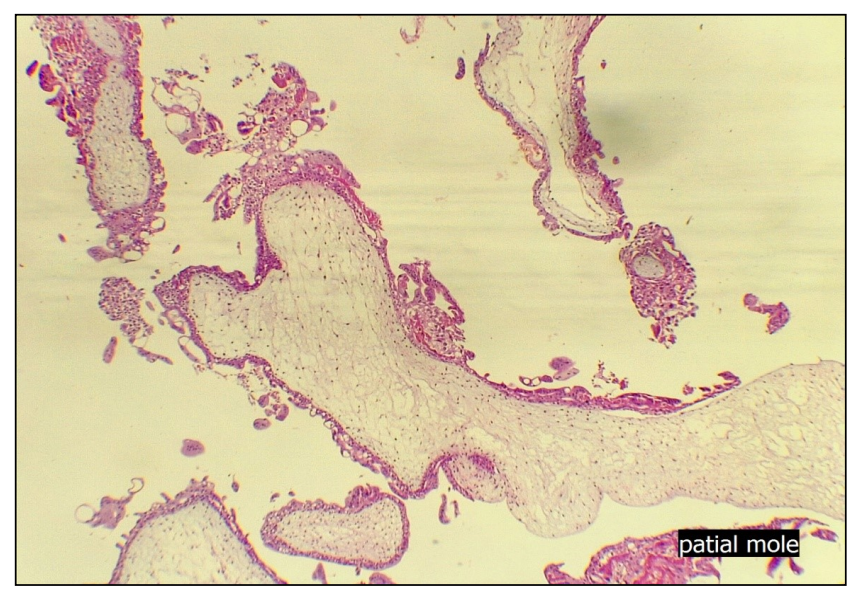

Figure 2: Hematoxyline and Eosin stained tissue section showing the histological features of partial mole (100x)

The application of Immunohistochemical staining with Ki67 antibody (Figure 4, 5 and 6) revealed varying degrees of positivity in both villous cytotrophoblasts and stromal cells, minimum, maximum and the mean numbers of stained nuclei for each study group were shown in Table I and II. None of syncytiotrophoblasts reacted with this antigen. Strong immunoreactivity in the nuclei of decidual cells, regarded as a positive internal control. 


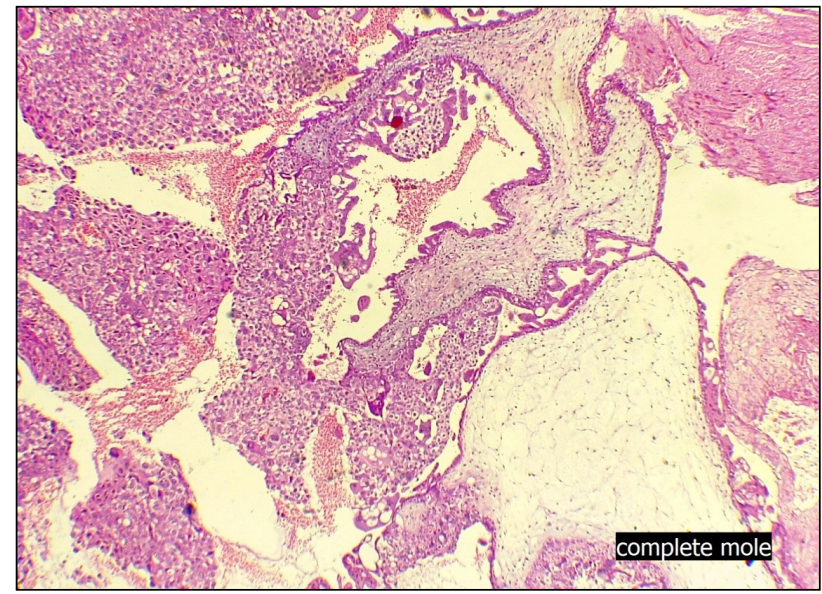

Figure 3: Hematoxyline and Eosin stained tissue section showing the histological features of complete mole (100x)

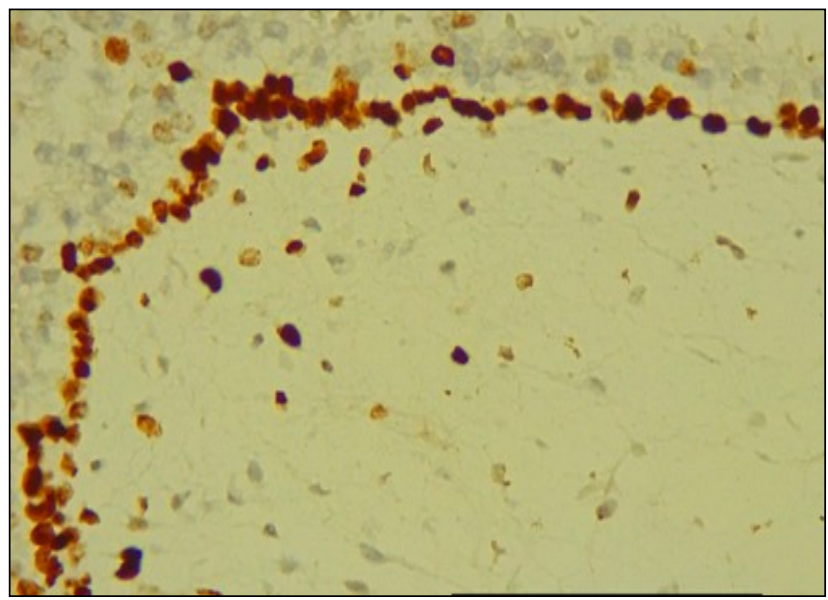

Figure 4: Ki67 immunohistochemically stained tissue section of chorionic villus in complete mole demonstrates the highest percentage of positive nuclear stains in both cytotrophoblasts and stromal cells among the study groups (200x)

There is a significant statistical relationship in Ki67 labeling index in both villous cytotrophoblasts and stromal cells between hydropic abortion and partial mole with a $p$ value less than 0.001 (Table III).

In a comparison between partial mole and complete mole, there is a significant statistical relationship achieved in Ki67 labeling index in

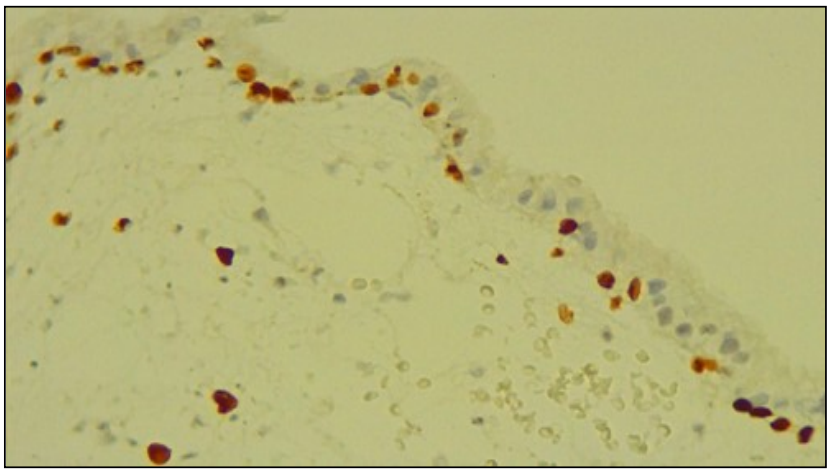

Figure 5: Ki67 immunohistochemically stained tissue section of chorionic villous in partial mole demonstrates positive nuclear stains in both cytotrophoblasts and stromal cells (200x)

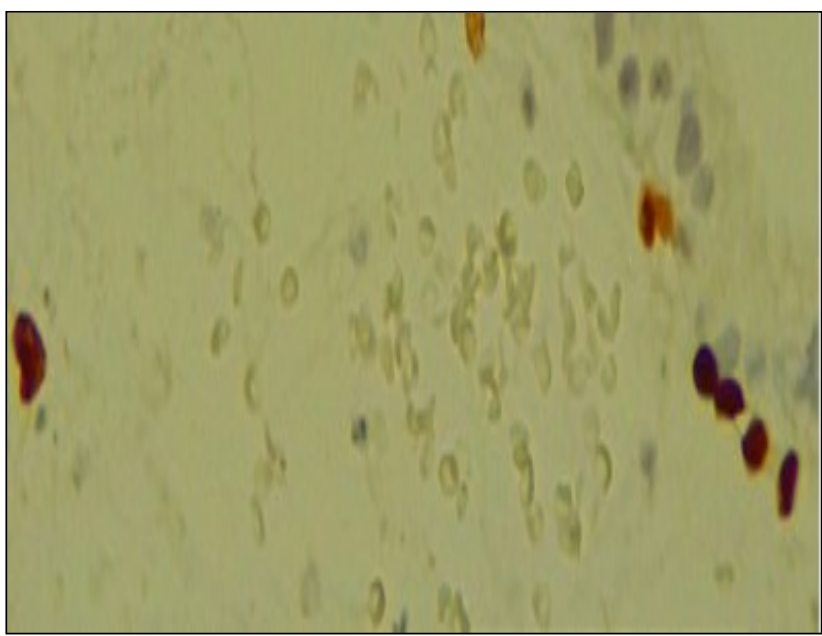

Figure 6: Ki67 immunohistochemically stained tissue sections of chorionic villus in hydropic abortion demonstrates the lowest percentage of nuclear positivity in both cytotrophoblasts and stromal cells among the study groups (400x)

villous cytotrophoblasts with a $p$ value less than 0.001 , while a non-significant statistical relationship in Ki67 labeling index achieved in villous stromal cells with $p$ value 0.21 (> 0.05) (Table III).

There is a significant statistical relationship in Ki67 labeling index in both villous cytotrophoblasts and

Table I: The mean value of Ki-67 Labeling Index (\% of Positively Stained Nuclei/Total Number of Nuclei Counted) in the three study groups

\begin{tabular}{|c|c|c|c|c|}
\hline $\begin{array}{l}\text { The study } \\
\text { groups }\end{array}$ & $\begin{array}{c}\text { Number of } \\
\text { cases }\end{array}$ & Cytotrophoblasts & Stromal Cells & Syncytiotrophoblasts \\
\hline $\begin{array}{l}\text { Hydropic } \\
\text { abortion }\end{array}$ & 30 & $6.53 \pm 0.81$ & $1.7 \pm 0.74$ & 0 \\
\hline Partial mole & 30 & $28.66 \pm 1.98$ & $4.966 \pm 1.35$ & 0 \\
\hline $\begin{array}{c}\text { Complete } \\
\text { mole }\end{array}$ & 30 & $54.06 \pm 1.31$ & $5.56 \pm 1.81$ & 0 \\
\hline
\end{tabular}


stromal cells between hydropic abortion and complete mole with a $p$ value less than 0.001 (Table III).

The distribution of Ki-67 labeling index of villous cytotrophoblasts among the three study groups showed that all cases of hydropic abortions displayed less than $20 \%$ index, all cases of partial mole displayed between 21 to $40 \%$ index and all cases of complete mole displayed more than $40 \%$ index. While in regard to villous stromal cells all the study groups displayed Ki67 index below 20\% (Table IV). agreed with two Iraqi studies done by Al-Baldawi ${ }^{2}$ and $\mathrm{Taboo}^{23}$ and a worldwide study done by Thama et al. ${ }^{3}$ So all agreed that gestational trophoblastic disease is a disease of young female.

The application of Immunohistochemical staining with Ki67 antibody revealed varying degrees of positivity in both villous cytotrophoblasts and stromal cells, while none of syncytiotrophoblasts reacted with this antigen, this results agreed with three studies worldwide. ${ }^{13,20,5}$ Because in contrast to cytotrophoblasts which are stem cells, syncytiotrophoblasts are terminally differentiated

Table II: Minimal and maximal numbers of positively stained cytotrophoblastic and stromal cells nuclei among the study groups.

\begin{tabular}{llllll}
\hline Non molar and molar villi & $\begin{array}{l}\text { Ki67 staining in cytotrophoblastic } \\
\text { nuclei }\end{array}$ & $\begin{array}{l}\text { Ki67 staining in stromal cell } \\
\text { nuclei }\end{array}$ \\
\hline The study groups & $\begin{array}{l}\text { Total number } \\
\text { of cases }\end{array}$ & $\begin{array}{l}\text { Minimal number } \\
\text { of positive cells }\end{array}$ & $\begin{array}{l}\text { Maximum number } \\
\text { of positive cells }\end{array}$ & $\begin{array}{l}\text { Minimal } \\
\text { number of } \\
\text { positive } \\
\text { cells }\end{array}$ & $\begin{array}{l}\text { Maximum } \\
\text { number of } \\
\text { positive cells }\end{array}$ \\
Hydrobic abortion & 30 & 5 & 8 & 1 & 3 \\
Partial mole & 30 & 25 & 31 & 3 & 8 \\
Complete mole & 30 & 50 & 55 & 3 & 9 \\
\hline
\end{tabular}

\section{DISCUSSION}

The strong recommendations for the use of immunohistochemistry in differentiation between hydropic abortion and partial mole or between types of hydatidiform mole, especially in early pregnancy are the aim of this study. Among the immunohistochemical antibodies, (Ki-67) regarded as a valuable marker for detecting tissue proliferation and it is widely available than p57 in most immunohistochemical laboratories. This study showed that the mean age of women with molar pregnancy was in the third decade of life which

Table III: Results of Statistical Analysis to Compare the mean value Ki-67 Expression between the three study Groups

\begin{tabular}{lll}
\hline & \multicolumn{2}{l}{ Results of statistical analysis } \\
\cline { 2 - 3 } $\begin{array}{l}\text { Comparison between } \\
\text { each two study groups }\end{array}$ & $\begin{array}{l}\text { Cytotrophoblasts } \\
\text { (p value) }\end{array}$ & $\begin{array}{l}\text { Stromal } \\
\text { cells } \\
\text { (p value) } \\
<0.001^{*}\end{array}$ \\
$\begin{array}{l}\text { Hydropic abortion } \\
\begin{array}{l}\text { and partial mole } \\
\text { Partial mole and com- } \\
\text { plete mole } \\
\text { Hydropic abortion and } \\
\text { complete mole }\end{array}\end{array}$ & $<0.001^{*}$ & $0.21^{* *}$ \\
\hline
\end{tabular}

cells that secrete most of placental hormones. A study done by Erfanian et al. ${ }^{8}$ surprisingly showed the positivity also present in syncytiotrophoblasts.

Comparison of Ki67 labeling index in villous cytotrophoblasts between hydropic abortion and partial mole and between partial and complete mole revealed a significant statistical relationship with $\mathrm{p}$ value $(<0.05)$. This result agreed with studies done by Erfanian _et al., Khooei et al and Chen et al. ${ }^{8,13,5}$, but disagrees with Cheville et al. ${ }^{6}$ which stated that growth fraction (number of positive cells/total number of cells) of Ki67 in cytotrophoblastic cells was useful in separating complete mole from partial mole, but not partial moles from hydropic abortion.

Erfanian_ et al. and Khooei et al. ${ }^{8,13}$ found a nonsignificant statistical relationship by correlation of Ki67 labeling index in villous stromal cells between hydropic abortion and partial mole and between partial and complete mole. 
Table IV: Distribution of the numbers of positive nuclear staining with Ki67 between the three study groups (H:hydropic abortion; P:partialmole; C:complete mole)

\begin{tabular}{|c|c|c|c|c|c|c|}
\hline \multirow{2}{*}{$\begin{array}{l}\text { Ki-67 Labeling } \\
\text { Index }\end{array}$} & \multicolumn{2}{|c|}{ Hydrobic abortion } & \multicolumn{2}{|c|}{ Partial mole } & \multicolumn{2}{|c|}{ Complete mole } \\
\hline & Cytotrophoblasts & $\begin{array}{l}\text { Stromal } \\
\text { cells }\end{array}$ & Cytotrophoblasts & $\begin{array}{l}\text { Stromal } \\
\text { cells }\end{array}$ & Cytotrophoblasts & Stromal cells \\
\hline $0-20$ & 30 & 30 & 0 & 30 & 0 & 30 \\
\hline $21-40$ & 0 & 0 & 30 & 0 & 0 & 0 \\
\hline More than 40 & 0 & 0 & 0 & 0 & 30 & 0 \\
\hline Total & 30 & 30 & 30 & 30 & 30 & 30 \\
\hline
\end{tabular}

However this study showed that there is a significant statistical relationship regarding Ki67 labeling index in villous stromal cells between hydropic abortion and partial mole while a non significant relationship achieved if the comparison done between partial and complete mole, there is no such previous similar Iraqi study on Ki67 expression in gestational trophoblastic disease. The variations in the reported results between studies may be related to many factors such as technical factors like the time of fixation (because the tissues used in these studies were archival retrieved with no standardized fixation time), variations in detection methods and sample size. Furthermore, the difference in gestational age between samples may affect the results of immunohistochemistry. There is a growing interest to apply a special Ki67 scoring system for each type of malignancy as a powerful prognostic parameter, this matter became routinely reported, particularly in breast, brain and neuroendocrine tumors. ${ }^{13}$ Our results can be regarded as an early attempt to create a comprehensive index in the form of a three tied score advised to be used during histomorphological evaluation of all curetting materials morphologically suspected to be of molar type products of conception for both diagnostic and prognostic purposes as below:

Score $1(+)$ less than $20 \%$, representing cases of hydropic abortion.

Score $2(++) \quad 21-40 \%$, representing cases of partial mole.

Score $3(+++)$ above $40 \%$, representing cases of complete mole.

This applications if became standardized will reduce the interobserver variations sometime associated with diagnosis and classification of hydatidiform mole and increase diagnostic accuracy of the complete mole because the higher association with persistent trophoblastic disease and choriocarcinoma which necessitates a thorough follow up.

\section{CONCLUSION}

Ki-67 labeling index in villous cytotrophblastic cells is useful in separating between hydropic abortion and partial mole, partial and complete mole, hydropic abortion and complete mole. While Ki-67 labeling index in villous stromal cells is useful in separating between hydropic abortion and partial mole, hydropic abortion and complete mole. The results of this study will help to raise awareness among Iraqi pathologists to apply (Ki67) in all curetting materials of molar pregnancies, especially if the morphological features of distinction were not clear cut.

\section{CONFLICT OF INTEREST}

None

\section{REFERENCES}

1. A Sita-Lumsden, D Short, I Lindsay, $\mathrm{N} \mathrm{J}$ Sebire, D Adjogatse, M J Seckl \& PM Savage .Treatment outcomes for 618 women with gestational trophoblastic tumors following a molar pregnancy at the Charing Cross Hospital, 2000-2009. British Journal of Cancer 2012, 107:1810-1814/

2. Al-Baldawi R. Retrospective Study On Management Of Gestational Trophoblastic Disease In Baghdad Teaching Hospital J Fac Med Baghdad Vol ,2013. 48 (3) : 262-66.

3. B.W.L. Thama, J.E. Everardb, J.A. Tidyc, D. Drewd, B.W. Hancock Gestational trophoblastic disease in the Asian population 
of Northern England and North Wales BJOG: an International Journal of Obstetrics and Gynaecology, 2003;110 : 555-559.

4. Carey L, Nash BM, Wright DC. Molecular genetic studies of complete hydatidiform moles. Transl Pediatr. 2015; 4(2):181-8.

5. Chen $Y$, Shen D, Gu Y, Zhong P, Xie J , So $\mathrm{Q}$.The diagnostic value of Ki-67, P53 and P63 in distinguishing partial Hydatidiform mole from hydropic abortion Wiener klinische Wochenschrift, ,2012;124(5)184-7.

6. Cheville JC, Robinson R, Benda JA. Evaluation of Ki-67 (MIB-1) in placentas with hydropic change and partial and complete hydatidiform mole. Pediatr Pathol Lab Med. 1966;16(1):41-50.

7. Clement PB, Young RH. Atlas of Gynecologic surgical pathology. Clement PB, Young RH. (eds). 3rd ed. Saunders Elsevier, London 2014;272-86.

8. Erfanian M, Sharifi N, and Ali A. P63 and $\mathrm{Ki}-67$ expression in trophoblastic disease and spontaneous abortion J Res Med Sci.2009; 14 (6): 375-84.

9. Fowler DJ, Lindsay I, Seckl MJ and Sebire NJ,. Routine pre-evacuation ultrasound diagnosis of hydatidiform mole: experience of more than 1000 cases from a regional referral center. Ultrasound Obstet Gynecol $2006 ; 27: 56-60$.

10. Garner El, Goldstein DP, Feltmate CM and Berkowitz RS. Gestational trophoblastic disease.Clin Obstet Gynecol 2007; 50(1):11222.

11. Ghanshyam Biyani and Pradeep Bhatia. Mortality in hydatidiform mole: Should we blame thyroid?. Indian J Anaesth 2011;55(6): 628-29.

12. Jessica Fernández, Rafael Cortés, Aleydah Salazar, Aníbal Pulido, Pablo Dabed and Victoria García. p57 kip2 immunohistochemistry: ancillary technique in hydatidiform moles diagnosis. BMC Proc 2013 ,7: 33.

13. Khooei A, Pasdar FA, Fazel A, Mahmoud iM, Nikravesh MR, Delui MK and Pourheydar B . Ki-67 Expression in Hydatidiform Moles and Hydropic Abortions Iran Red Crescent Med J ,2013;15(7): 590-594.

14. Kubelka-Sabit K, Jasar D, Filipovski V,
Bozinovski G, Plaseska-Karanfilska D. Molecular and histological characteristics of early triploid and partial molar pregnancies. Pol J Pathol 2017; 68(2):138-143.

15. Lai CY, Chan KY, Khoo US, Ngan HY, Xue WC, Chiu PM et tal. . Analysis of gestational trophoblastic disease by genotyping and chromosome in situ hybridization. Mod Pathol 2004;17(1):40-8.

16. Lurain JR. Advances in management of highrisk gestational trophoblastic tumors. J Reprod Med. 2002;47(6):451-9.

17. Mahzouni $\mathrm{P}$, Mokhtari M, Amirmansour B.. Diffrentiation between reactive gliosis and astrocytomas by MIB-1/Ki67 immunostaining. J Res Med Sci.2007;12(5):241-5.

18. McConnell TG, Murphy KM, Hafez M, Vang R, Ronnett BM. Diagnosis and subclassification of hydatidiform moles using p57 immunohistochemistry and molecular genotyping: validation and prospective analysis in routine and consultation practice settings with development of an algorithmic approach.Am J Surg Pathol 2009 ;33(6):805-17.

19. Neil J Sebire, Philippa C May, Baljeet Kaur, Michael J Seckl, and Rosemary A

Fisher.Abnormal villous morphology mimicking a hydatidiform mole associated with paternal trisomy of chromosomes $3,7,8$ and unipaternal disomy of chromosome 11 Diagn

Pathol,2016;11: 20.

20. Olvera M, Harris S, Amezcua CA, McCourty A, Rezk $S$, Koo $C$ et al.. Immunohistochemical expression of cell cycle proteins E2F-1, Cdk-2, Cyclin E, p27 (kip1), and Ki-67 in normal placenta and gestational trophoblastic disease. Mod Pathol ,2001;14(10):1036-42.

21. Rosai J. Ackerman's surgical pathology. 10 ed. Female reproductive system St Louis: Mosby, 2011; pp. 1639-45.

22. Smith HO, Kohorn E, Cole LA. Choriocarcinoma and gestational trophoblastic disease. Obstet Gynecol Clin North Am 2005 ;32(4):661-84.

23. Taboo ZA . A Prospective Study of Gestational Trophoblastic Disease in Al-Mosul City. The Iraqi post graduate medical journa. 2013;12 (2):268-76.

24. Tham BWL, Everard JE, Tidy JA, Drew D, Hancock BW. Gestational trophoblastic disease in the Asian population of Northern England and North Wales. BJOG 2003 ;110:555-9. 